\title{
Synthesis of potential related substances of mirtazapine
}

\author{
Divvela V. N. Srinivasa Rao, ${ }^{\text {a }}$ Ramesh Dandala, ${ }^{a^{*}}$ Chalamakuri Bharathi, ${ }^{a}$ \\ Vijay Kumar Handa, ${ }^{a}$ Meenakshisunderam Sivakumaran, ${ }^{a}$ and Andra Naidu ${ }^{b}$ \\ ${ }^{a}$ Chemical Research Department, APL Research Centre, Hyderabad-500 072, India \\ ${ }^{b}$ J. N. T. University, Kukatpally, Hyderabad-500 072, Andhra pradesh, India \\ E-mail: rdandala@aurobindo.com
}

\begin{abstract}
The synthesis of three contaminants of mirtazapine 6 , formed during the preparation of mirtazapine bulk drug, is described. The products are 2-methyl-1,2,3,4,10,14bhexahydrobenzo[c]pyrazino(1,2-a)pyrido[3,2-f]azepine-2-oxide $\quad(N$-oxide, $\quad 7), \quad 1-(3-$ methylpyridyl-2)-2-phenyl-4-methylpiperazine (deshydroxy compound, 9), and 2-methyl1,2,3,4,10,14b-hexahydro-10-oxo-benzo[c] pyrazino (1,2-a)pyrido[3,2-f]azepine (oxo compound 11). The structures of these compounds were established on the basis of spectral data (IR, ${ }^{1} \mathrm{H}-$ NMR and MS).
\end{abstract}

Keywords: 1-Methyl-3-phenylpiperazine, 2-chloronicotinonitrile, oxidation, bulk drug, synthesis, contaminants

\section{Introduction}

Mirtazapine 6, chemically known as 2-methyl-1,2,3,4,10,14b-hexahydrobenzo[c]pyrazino(1,2a)pyrido[3,2-f]azepine, is approved, under the trademark Remeron, by the U.S. Food and Drug Administration for the treatment of depression. Mirtazapine 6 has a tetracyclic chemical structure unrelated to other classes of antidepressants such as selective serotonin reuptake inhibitors, tricyclics or monoamine oxidase inhibitors. ${ }^{1,2}$ Several methods are reported in the literature for the preparation of mirtazapine, ${ }^{3-5}$ but the related compound synthesis has not been discussed, although these impurities were studied in the tablets. ${ }^{6}$ The preparation and characterization data of these related substances has been necessary for the preparation of reference compounds for the quality assurance of bulk drug substance and drug formulations. 


\section{Results and Discussion}

Mirtazapine $\mathbf{6}$ was prepared starting from 1-methyl-3-phenylpiperazine ${ }^{7} \mathbf{1}$ by following a known $\operatorname{method}^{3}$ (Scheme 1). It was observed during the process development of mirtazapine 6 that some of the batches of $\mathbf{6}$ were contaminated with these impurities 7, 9 and $\mathbf{1 1}$ in the range from $0.1 \%$ to $0.5 \%$. These impurities were synthesized after identification by HPLC and detection of mass by LC-MS. It was necessary to synthesize these impurities 7, 9 and $\mathbf{1 1}$ in pure form for analytical method validation of mirtazapine 6 bulk drug. Therefore, a comprehensive study was carried out to prepare these contaminants.<smiles>CN1CCNC(c2ccccc2)C1</smiles>

1<smiles>N#Cc1cccnc1Cl</smiles>

2<smiles>CN1CCN(c2ncccc2C#N)C(c2ccccc2)C1</smiles>

3

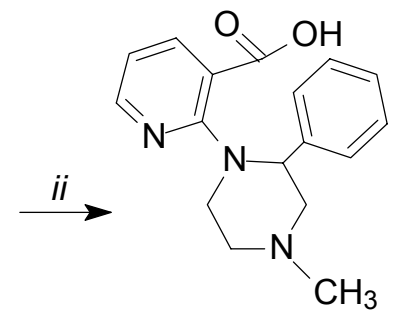

4

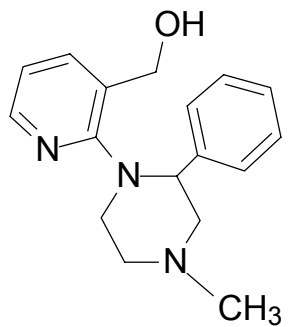

5

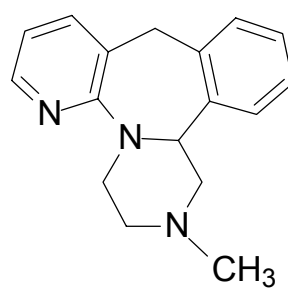

6

Scheme 1. i. KF, DMF, $140{ }^{\circ} \mathrm{C}$; ii. $\mathrm{KOH}, \mathrm{EtOH}$, reflux. iii. $\mathrm{LiAlH}_{4}$, THF, reflux. iv. $\mathrm{H}_{2} \mathrm{SO}_{4}$, rt.

$\mathrm{N}$-oxide formation is very common in nitrogen compounds. In most of the times, the elimination of this impurity from the finished product is very difficult. $N$-oxide 7 was observed up to $0.3 \%$ of the product in some batches prepared in our laboratory. It was also observed during the degradation studies of this product. Therefore it was necessary to prepare this compound in pure form for the validation study of the bulk drug. It was prepared by the oxidation of mirtazapine 6 in $90 \%$ yield by using peracetic acid as an oxidizing agent (Scheme 2). 


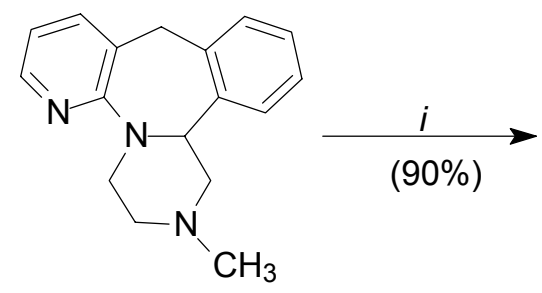

6

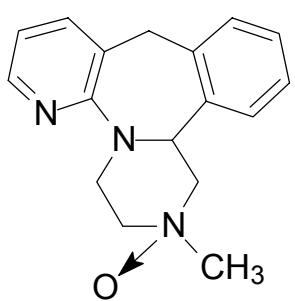

7

Scheme 2. i. $\mathrm{CH}_{3} \mathrm{CO}-\mathrm{OOH}, \mathrm{CH}_{2} \mathrm{Cl}_{2}$, rt.

It was observed that during the reduction of carboxylic acid group with $\mathrm{LiAlH}_{4}$, over reduction leading to the formation of the deshydroxy compound 9 in the range from $0.2 \%$ to $0.7 \%$. Compound 5 was treated with methanesulphonyl chloride in the presence of triethylamine to obtain the corresponding mesyl derivative $\mathbf{8}$, which was subjected to reduction with $\mathrm{LiAlH}_{4}$ to give compound 9 (Scheme 3).<smiles>CN1CCN(c2ncccc2CO)C(c2ccccc2)C1</smiles>

5<smiles>CN1CCN(c2ncccc2COS(C)(=O)=O)C(c2ccccc2)C1</smiles>

8

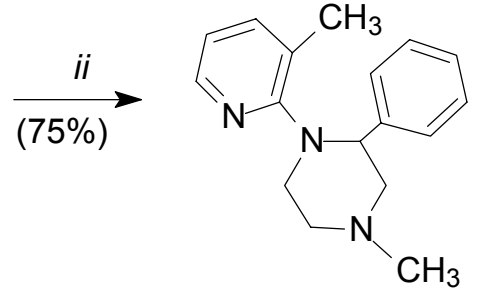

9

Scheme 3. i. $\mathrm{CH}_{3} \mathrm{SO}_{2} \mathrm{Cl}, \mathrm{CH}_{2} \mathrm{Cl}_{2}$, reflux; ii. $\mathrm{LiAlH}_{4}$, THF, reflux.

Oxo compound 11 was formed due to the oxidation of benzylic methylene at carbon 10. This compound was prepared by treating the acid $\mathbf{4}$ with thionyl chloride at reflux to obtain the corresponding acid chloride 10, which was subsequently cyclised with anhydrous $\mathrm{AlCl}_{3}$ in methylene chloride to give the oxo compound 11 (Scheme 4).
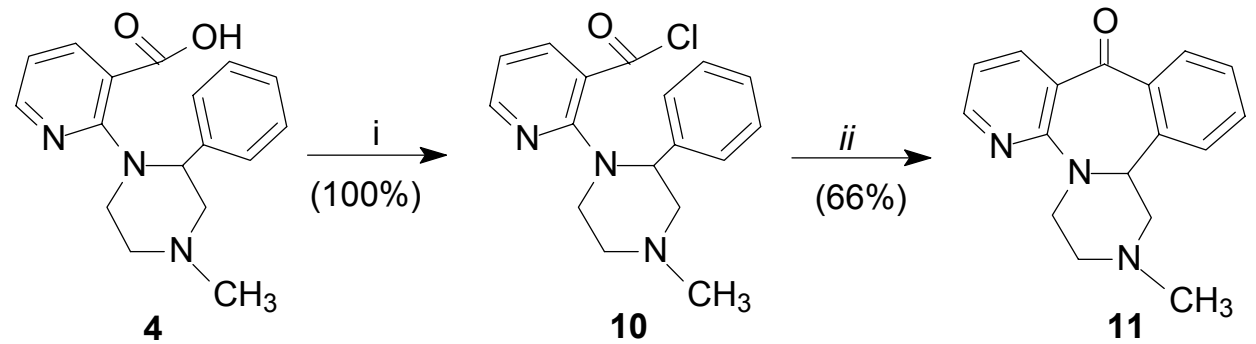

Scheme 4. i. $\mathrm{SOCl}_{2}$, TEA, $\mathrm{CH}_{2} \mathrm{Cl}_{2}$, reflux; ii. $\mathrm{AlCl}_{3}, \mathrm{CH}_{2} \mathrm{Cl}_{2}$, rt. 
In summary, we report methods for the preparation of the common contaminants of mirtazapine in quite good yield and purity. Also, the spectral data (IR, 1H-NMR and MS) of these compounds were described.

\section{Experimental Section}

General Procedures. All melting points were determined with a Polmon melting point apparatus. ${ }^{1} \mathrm{H}-\mathrm{NMR}$ and ${ }^{13} \mathrm{C}-\mathrm{NMR}$ spectra were recorded on a Bruker 300 spectrometer. Chemical shifts are reported in ppm downfield from TMS as internal standard. Mass spectra were measured on a Perkin Elmer PE SCIEX-API 2000 mass spectrometer. Elemental analyses were performed using a Heraeus CHN-O-Rapid instrument. Analytical HPLC ${ }^{8}$ were run with Symmetry $\mathrm{C}_{18}, 250$ x $4.6 \mathrm{~mm}$ column at $290 \mathrm{~nm}$. "RT" denotes room temperature.

2-Methyl-1,2,3,4,10,14b-hexahydrobenzo[c]pyrazino(1,2-a)pyrido[3,2-f]azepine-2-oxide (7). Per acetic acid solution $(30 \% \mathrm{w} / \mathrm{w}, 10.0 \mathrm{~g}, 39.45 \mathrm{mmol})$ was added drop wise to a solution of mirtazapine $(10.0 \mathrm{~g}, 37.74 \mathrm{mmol})$ in methylene chloride $(60 \mathrm{~mL})$ at $5-10{ }^{\circ} \mathrm{C}$ in a period of 20 min. The reaction mass was stirred at $5-10{ }^{\circ} \mathrm{C}$ for $30 \mathrm{~min}$. and then stirred at $25-30{ }^{\circ} \mathrm{C}$ for $4 \mathrm{~h}$. The reaction mixture was washed with water $(10 \mathrm{~mL})$ and evaporated. Diisopropyl ether $(50 \mathrm{~mL})$ was added to the residue, filtered the product and washed with diisiopropyl ether $(10 \mathrm{~mL})$, dried, to yield 7 (9.55 g, 90\%) as a white solid; purity $99.5 \%$ (by HPLC), $\mathrm{mp} 98-99{ }^{\circ} \mathrm{C}$; IR $\left(\mathrm{KBr}, \mathrm{cm}^{-1}\right.$ ) 2950, 1590, 1494, 1439, 1381, 1350, 788, 764; ${ }^{1} \mathrm{H}-\mathrm{NMR}\left(300 \mathrm{MHz}, \mathrm{CDCl}_{3}\right) \delta 3.36$ (s, 3H), 3.39$3.44(\mathrm{~m}, 2 \mathrm{H}), 3.52-3.60$ (m, 3H), 3.63-3.77 (m, 1H), 4.19-4.23 (m, 1H), 4.48 (d, 1H, J=13.4 Hz), $5.22(\mathrm{dd}, 1 \mathrm{H}, J=10.7,2.5 \mathrm{~Hz}), 6.81(\mathrm{dd}, 1 \mathrm{H}, J=7.2,5.2 \mathrm{~Hz}), 7.15-7.28(\mathrm{~m}, 4 \mathrm{H}), 7.35(\mathrm{dd}, 1 \mathrm{H}$, $J=7.5,2.0 \mathrm{~Hz}), 8.19(\mathrm{dd}, 1 \mathrm{H}, J=5.0,1.9 \mathrm{~Hz}) ;{ }^{13} \mathrm{C}-\mathrm{NMR}\left(75 \mathrm{MHz}, \mathrm{CDCl}_{3}\right) \delta 38.6,44.6,60.0$, $61.1,66.5,73.7,118.5,128.0,128.5,128.8,130.6,132.2,134.4,135.0,138.6,146.8,158.5$; MS (ESI, $m / z): 282.2[\mathrm{M}+\mathrm{H}]^{+}$. Anal. Calcd. For $\mathrm{C}_{17} \mathrm{H}_{19} \mathrm{~N}_{3} \mathrm{O}$ (281.36): C, 72.57; H, 6.81; N, 14.93 . Found: C, 72.39; H, 6.89; N, 14.78 .

1-(3-Methylpyridyl-2)-2-phenyl-4-methylpiperazine (9). Under $\mathrm{N}_{2}$ atmosphere, methane sulphonyl chloride $(4.86 \mathrm{~g}, 42.45 \mathrm{mmol})$ was added to a solution of compound 5 (10.0 g, 35.34 mmol), triethyl amine $(5.35 \mathrm{~g}, 52.97 \mathrm{mmol})$ in methylene chloride $(60 \mathrm{~mL})$ at $0-5{ }^{\circ} \mathrm{C}$ and stirred at $25-30{ }^{\circ} \mathrm{C}$ for $12 \mathrm{~h}$. Thereafter, heated to reflux for $2 \mathrm{~h}$. Cooled the mass to $25-30{ }^{\circ} \mathrm{C}$ and washed with water $(20 \mathrm{~mL})$ and evaporated to get the mesyl derivative $8(10.22 \mathrm{~g}, 80 \%)$. This residue, without purification, was dissolved in THF $(100 \mathrm{~mL})$ and was added $\mathrm{LiAlH}_{4}{ }^{9}(5.37 \mathrm{~g}$. $141.32 \mathrm{mmol}$ ) at $0-5{ }^{\circ} \mathrm{C}$ under $\mathrm{N}_{2}$ atmosphere. The reaction mass was heated to reflux for $15 \mathrm{~h}$. The excess $\mathrm{LiAlH}_{4}$ was destroyed at $0{ }^{\circ} \mathrm{C}$ with water $(5.4 \mathrm{~mL}), 15 \% \mathrm{NaOH}(5.4 \mathrm{~mL})$ and water $(16.2 \mathrm{~mL})$. After filtration, the filtrate was evaporated to dryness and diisopropyl ether $(40 \mathrm{~mL})$ was added. Filtered the product and washed with diisiopropyl ether $(10 \mathrm{~mL})$, dried, to yield 9 (5.66 g, 75\%) as a white solid; purity $99.1 \%$ (by HPLC), $\mathrm{mp} 108-109{ }^{\circ} \mathrm{C}$; IR ( $\mathrm{KBr}, \mathrm{cm}^{-1}$ ) 2866 , 2854, 2786, 1601, 1493, 1450, 1371, 1353, 791, 759, 744, 700; ${ }^{1} \mathrm{H}-\mathrm{NMR}\left(300 \mathrm{MHz}, \mathrm{CDCl}_{3}\right) \delta$ 
$2.17(\mathrm{t}, 1 \mathrm{H}, J=10.7 \mathrm{~Hz}), 2.34(\mathrm{~s}, 3 \mathrm{H}), 2.36(\mathrm{~s}, 3 \mathrm{H}), 2.43(\mathrm{~m}, 1 \mathrm{H}), 2.85-2.97(\mathrm{~m}, 3 \mathrm{H}), 3.12-3.15$ (m, 1H), $4.70(\mathrm{dd}, 1 \mathrm{H}, J=10.3,3.3 \mathrm{~Hz}), 6.73(\mathrm{~m}, 1 \mathrm{H}), 7.01-7.13(\mathrm{~m}, 3 \mathrm{H}), 7.28-7.33(\mathrm{~m}, 3 \mathrm{H}), 7.98$ $(\mathrm{dd}, 1 \mathrm{H}, J=4.6,2.2 \mathrm{~Hz}) ;{ }^{13} \mathrm{C}-\mathrm{NMR}\left(75 \mathrm{MHz}, \mathrm{CDCl}_{3}\right) \delta 17.8,46.6,52.3,56.0,62.1,64.4,119.6$, 126.8, 127.8, 128.2, 128.3, 139.1, 143.0, 146.1, 161.8; MS (ESI, $m / z): 268.2[\mathrm{M}+\mathrm{H}]^{+}$. Anal. Calcd. For $\mathrm{C}_{17} \mathrm{H}_{21} \mathrm{~N}_{3}$ (267.38): C, 76.37; H, 7.92; N, 15.71. Found: C, 76.42; H, 7.69; N, 15.89.

2-Methyl-1,2,3,4,10,14b-hexahydro-10-oxobenzo[c]pyrazino(1,2-a)pyrido[3,2-f]azepine

(11). Mixture of compound $4(10.0 \mathrm{~g}, 33.67 \mathrm{mmol})$ and thionyl chloride (11.22 g, $94.29 \mathrm{mmol})$ was heated to reflux for $4 \mathrm{~h}$. After removal of thionyl chloride under reduced pressure, was added methylene chloride $(100 \mathrm{~mL})$ to resulted acid chloride 10 (10.63 g, 100\%). To this mass, was added $\mathrm{AlCl}_{3}(11.57 \mathrm{~g}, 86.77 \mathrm{mmol})$ at $5-10{ }^{\circ} \mathrm{C}$ in $30 \mathrm{~min}$. and stirred at $25-30{ }^{\circ} \mathrm{C}$ for $2 \mathrm{~h}$. Thereafter, the reaction mass was added to pre-cooled water $(300 \mathrm{~mL})$. Basified the mass with $40 \%$ sodium hydroxide solution and filtered to remove the undissolved matter. The organic layer was separated and washed with water $(20 \mathrm{~mL})$ and evaporated. The residue was treated with diisopropyl ether $(40 \mathrm{~mL})$, filtered the product and washed with diisiopropyl ether $(5 \mathrm{~mL})$, dried, to yield $11\left(6.24 \mathrm{~g}, 66 \%\right.$ ) as a yellow solid; purity 99.5\% (by HPLC), mp $155-156{ }^{\circ} \mathrm{C}$; $\mathrm{IR}(\mathrm{KBr}$, $\left.\mathrm{cm}^{-1}\right) 2883,2855,1633,1595,1462,1364,1343,1296,780,766 ;{ }^{1} \mathrm{H}-\mathrm{NMR}\left(300 \mathrm{MHz}, \mathrm{CDCl}_{3}\right) \delta$ 2.36-2.41 (m, 1H), $2.45(\mathrm{~s}, 3 \mathrm{H}), 2.55-2.59(\mathrm{~m}, 1 \mathrm{H}), 3.03(\mathrm{~d}, 1 \mathrm{H}, J=11.3 \mathrm{~Hz}), 3.17-3.22(\mathrm{~m}, 1 \mathrm{H})$, $3.38(\mathrm{~d}, 1 \mathrm{H}, J=11.3 \mathrm{~Hz}), 4.43$ (d, 1H, $J=4.5 \mathrm{~Hz}), 4.89-4.93(\mathrm{~m}, 1 \mathrm{H}), 6.87$ (dd, 1H, J=7.9, $4.5 \mathrm{~Hz})$, 7.37-7.39 (m, 1H). 7.57-7.59 (m, 2H), 8.04 (d, 1H, J=7.6 Hz), 8.37-8.39 (m, 1H), 8.52 (dd, 1H, $J=7.9,2.1 \mathrm{~Hz}) ;{ }^{13} \mathrm{C}-\mathrm{NMR}\left(75 \mathrm{MHz}, \mathrm{CDCl}_{3}\right) \delta 41.8,46.8,53.4,55.7,56.6,115.1,118.9,126.5$, 128.2, 128.4, 132.6, 139.7, 140.3, 141.2, 153.0; MS (ESI, $m / z): 280.2[\mathrm{M}+\mathrm{H}]^{+}$. Anal. Calcd. For $\mathrm{C}_{17} \mathrm{H}_{17} \mathrm{~N}_{3} \mathrm{O}$ (279.34): C, 73.09; H, 6.13; N, 15.04. Found: C, 73.37; H, 6.02; N, 15.22.

\section{Acknowledgements}

The authors thank the management of Aurobindo Pharma Limited, Hyderabad for permission to publish this work. The authors also thank the Analytical Research Department for their valuable contribution to this work.

\section{References and Footnotes}

1. De Boer, T.; Maura, G.; Raiteri, M.; De Vos, J.; Wieringa, J.; Pinder, R. P. Neuropharmacology 1988, 27, 399.

2. De Boer, T.; Ruight, G. S. F.; Berendsen, H. G. Human psychopharm. 1995, 10, 107.

3. Van der Burg, W. J. Ger. Offen. 2, 614, 406, 1975: Chem. Abstr. 1977, 86, 29883.

4. Singer, A.; Liberman, A.; Finkelstein, N. PCT Int. Appl. WO 62, 782, 2000; Chem. Abstr. 2000, 133, 321900.

5. Iishi, K.; Yoshikawa, K. US Patent 6,437,120, 2002; Chem. Abstr. 2001, 135, 33494. 
6. Wynia, G.; Windhorst, G.; Post, P. C.; Maris, M. J. Chromatography. 1997, A 773, 339.

7. Srinivasarao, D. V. N.; Ramesh, D.; Handa, V. K.; Sivakumaran, M.; Naidu, A. Arkivoc 2006, (xiv), 1.

8. HPLC analyses were carried out only for compounds 7, 9 and 11. Retention times were 2.9, 27.5 and 33.7 respectively $\left(\mathrm{CH}_{3} \mathrm{CN}\right.$ : $\left.0.05 \mathrm{M} \mathrm{KH}_{2} \mathrm{PO}_{4}\right)$.

9. Lithium Aluminum Hydride reacts violently with water, liberating hydrogen, incompatible with strong oxidizing agents. Reactions to be carried out in anhydrous conditions. 